\title{
Effect of spa treatment and the epidemiology of tuberculosis in the Slovak republic in the year 2014
}

\author{
M. Samohyl1, I. Solovic 2,3, R. Rams 3,4, K. Hirosova?', \\ D. Vondrova', D. Krajcova', A. Nadazdyova5, A. Filova', \\ J. Jurkovicova'
}

Original Articles

${ }^{1}$ Institute of Hygiene, Faculty of Medicine, Comenius University, Bratislava, Slovak Republic

${ }^{2}$ Institute of Tuberculosis, Lung Diseases and Thoracic Surgery, Vysne Hagy, Slovak Republic

${ }^{3}$ Faculty of Health, Catholic University, Ruzomberok, Slovak Republic

${ }^{4}$ Institute of Public Health, Jessenius Medical Faculty Comenius University, Martin, Slovak Republic

${ }^{5}$ Department of Stomatology and Maxillofacial Surgery, Faculty of Medicine, Comenius University, Bratislava, Slovak Republic

\section{Correspondence to:}

Institute of Hygiene, Faculty of Medicine, Comenius University in Bratislava, Spitalska 24, 81372 Bratislava, Slovak Republic; e-mail: martin.samohyl@fmed.uniba.sk

Submitted: 26.8 .2016

Revised: 20.7.2016

Accepted: 12.8 .2016

\section{Reviewers:}

V. Krcmery

Institute of Microbiology, Faculty of Medicine of Comenius University and University Hospital Bratislava, Slovak Republic

J. Suvada

St. Charles Foucauld Health Centre, St. Elisabeth University, Beirut, Lebanon

\section{Key words:}

Tuberculosis, epidemiology, TB prevalence, treatment success.

CSWHI 2016; 7(2): 24-35 @ 2016 Clinical Social Work and Health Intervention

\section{Abstract:}

Tuberculosis (TB) is an infectious disease characterized by specific granular inflammation and granuloma (tuberculoma) formation. In the Slovak Republic, there were 336 cases of TB in the year 2014, which signifies a prevalence of $6.20 / 100,000$ in the total population. The TB prevalence decreased by about $1.21 / 100,000$ population compared to the year 2013. The proportion of extra-pulmonary TB was 59 cases to 277 cases of pulmonary TB. The highest incidence of TB in women was in the age group $0-4$ years (19 cases), and in men in the age of 50 
- 54 years (27 cases). The highest prevalence of TB was in the Presov Region (13.07/100,000) and in Kosice Region (8.05/100,000), the lowest TB prevalence was in Trnava Region (3.23/100,000). The TB prevalence in childhood was 45 cases, of which 39 cases were in Roma children. The highest prevalence of TB in childhood was in the Presov Region (22.24/100,000) and Banska Bystrica Region (4.35/100,000). The Slovak Republic reached the highest percentage of successful TB treatment $(85 \%)$ in newly diagnosed microscopically positive cases among European countries. The incidence of TB in Slovakia decreased over recent years, but nevertheless, more attention should be paid to looking for patients, particularly in high-risk population groups.

\section{Introduction}

Tuberculosis is an infectious disease characterized by specific granular inflammation and granuloma formation - tubercles. Tuberculosis usually affects the lungs (75\%), but TB can also affect other parts of the body (bones, joints, heart, muscles, skin, pancreas, digestive tract, thyroid, kidneys, brain, etc.) - this is the so-called extra-pulmonary TB (25\% of cases) (RPHA, 2014; Solovic, 2014). Extra-pulmonary TB more often occurs in immunocom-promised patients and in very young children. Tuberculosis is an air-borne infection spread by coughing and/or sneezing patient with the active TB. Most infected people (90\%) have asymptomatic, latent forms of TB. Miliary TB is the most dangerous form, which attacks several organs simultaneously. Extra-pulmonary and pulmonary tuberculosis can run simultaneously (RPHA, 2014).

Tuberculosis is mainly caused by the bacteria Mycobacterium tuberculosis, less frequently by Mycobacterium Bovis and Mycobacterium Africanum. Around one third of the world population has been infected by the Mycobacterium tuberculosis (Dye et al., 1999; Frieden et al., 2003). The bacteria $M$. tuberculosis are expectorated by patients with active pulmonary TB typically by coughing. The active transmission in the countries with high TB incidence most often happens in households and crowded spaces with large numbers of people. The risk of infection depends on several factors: degree of the reservoir infectivity; contact closeness; quantity of inhaled bacteria; and the condition of the host immune system (Solovic, 2008).

The worldwide annual incidence of active TB forms is more than 8 million, with more than $90 \%$ of deaths in developing countries, so tuberculosis remains one of the most important global threats in public health (Ahlburg 2000; Maher, Raviglione, 2005;

Gupa et al., 2004). Tuberculosis is the most common cause of death of all treatable infectious diseases (Dye, 2006).

Since 2006, TB prevalence in the European Union (EU) has dropped annually on average by $4.4 \%$ (ECDC, 2012). The TB prevalence decrease can be attributed to the better national and international TB monitoring (Glaziou et al., 2013). In the developed countries, the TB prevalence has dramatically fallen, but in these countries it is still relatively high. (Mathema et al., 2006).

Currently, despite the new quantiferon TB tests (Zanova et al., 2012), and accessible and efficient anti-tuberculotic drugs, TB 
remains after more than 50 years a significant global health problem (Mathema et al., 2006).

\section{TB Epidemiology in Slovakia in 2014}

The prediction of the TB incidence decrease in Slovakia, relevant in the 1980s of the 20th Century, is now being fulfilled. The highest TB prevalence in Slovakia was in 1960 when there were 7,817 registered TB cases, and since then it has a declining trajectory. According to the National TB Registry (NRT) statistics, the absolute number of reported cases decreased up to 1970. In the second half of the 1980s the decline was even more significant. In 2002, there were 1,053 reported cases of newly diagnosed TB and in 2003 the number of newly diagnosed cases was less than one thousand for the first time.

Nowadays, the incidence situation is stabilized in Slovakia. In 2013, 401 TB cases were reported to the NRT (prevalence of 7.41/100,000 population). In 2014, 336 TB cases were reported (prevalence of $6.2 / 100,000$ population), of which 42 were relapses (Fig. 1). In 2014, compared to 2013 , there was a decrease of TB prevalence by $1.21 / 100,000$ population. The pulmonary forms of tuberculosis accounted for 277 cases and 59 cases involved extra-pulmonary TB. Comparison by sex and age showed more diagnosed cases in men (nearly of 200), while in women TB occurrence is predominantly in the older age groups. In 2014, no cases of co-infection of TB and HIV were reported. In total, $222 \mathrm{~TB}$ cases were verified $(66.1 \%)$ - by bacteriological, histological and other methods.

Since 1988, the highest number of cases/ incidence of pulmonary and extra-pulmonary TB forms was in 1993 and the lowest in 2014 (277 of pulmonary and 59 of extra-pulmonary cases). Since 1993, the incidence of pulmonary and extra-pulmonary TB has a descending tendency (Fig. 2).

In 2014, a higher TB incidence was in men in age groups 25 - 79 years than in women, with the highest incidence in the 50 - 54 age group (27 cases). In women there was a higher TB incidence in the 0 - 19 age group, with the highest TB incidence in the 0 - 4 age group (19 cases) (Fig. 3).

Fig. 1 The TB prevalence in Slovakia, 1960 to 2014 (adapted according to National TB Registry, 2014)

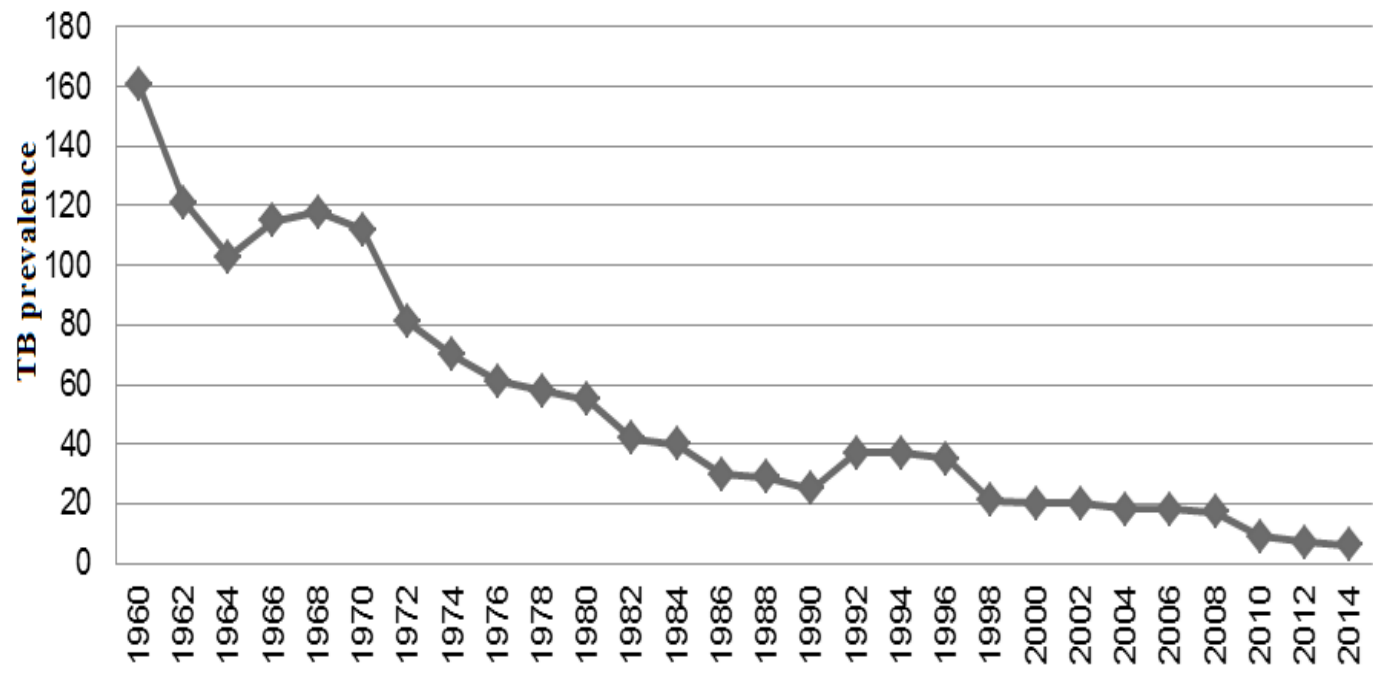


Fig. 2 TB cases during the years 1988 to 2014 (adapted according to National TB Registry, 2014)

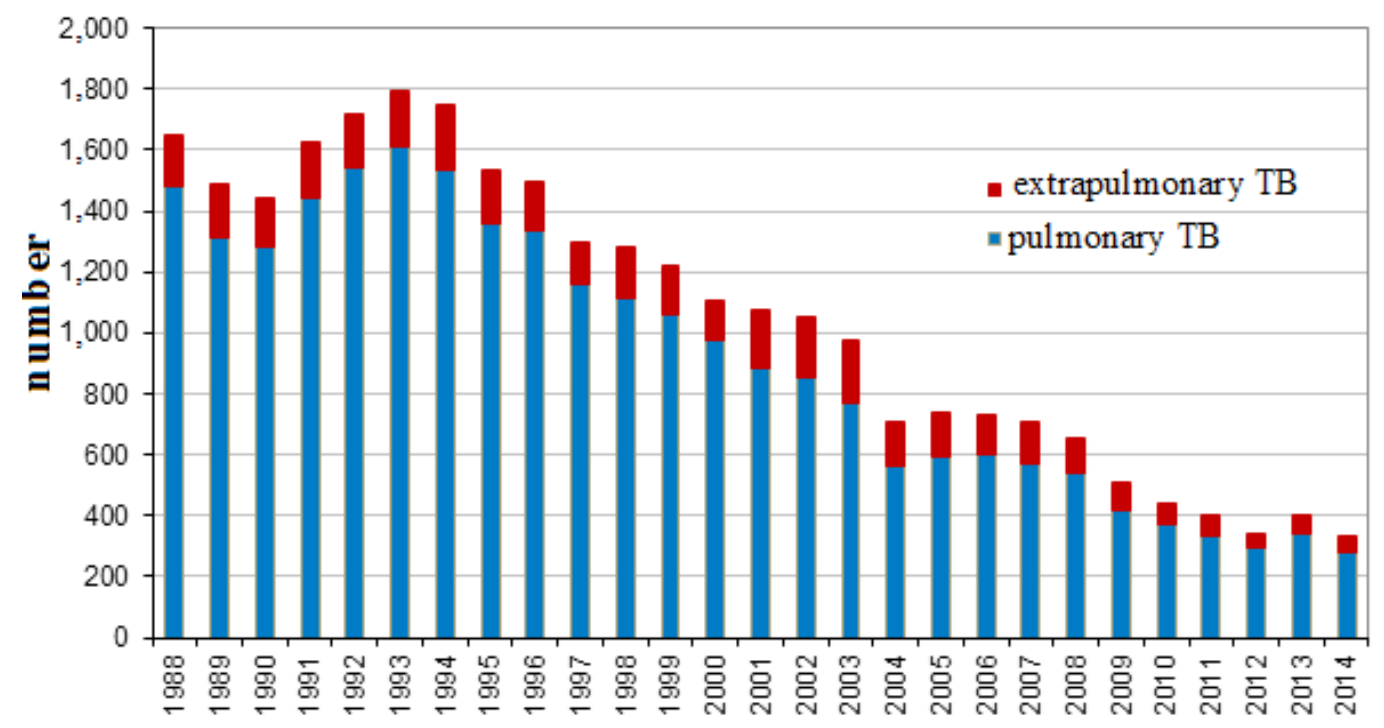

Fig. 3 The TB cases by age and sex, 2014 (adapted according to National TB Registry, 2014)

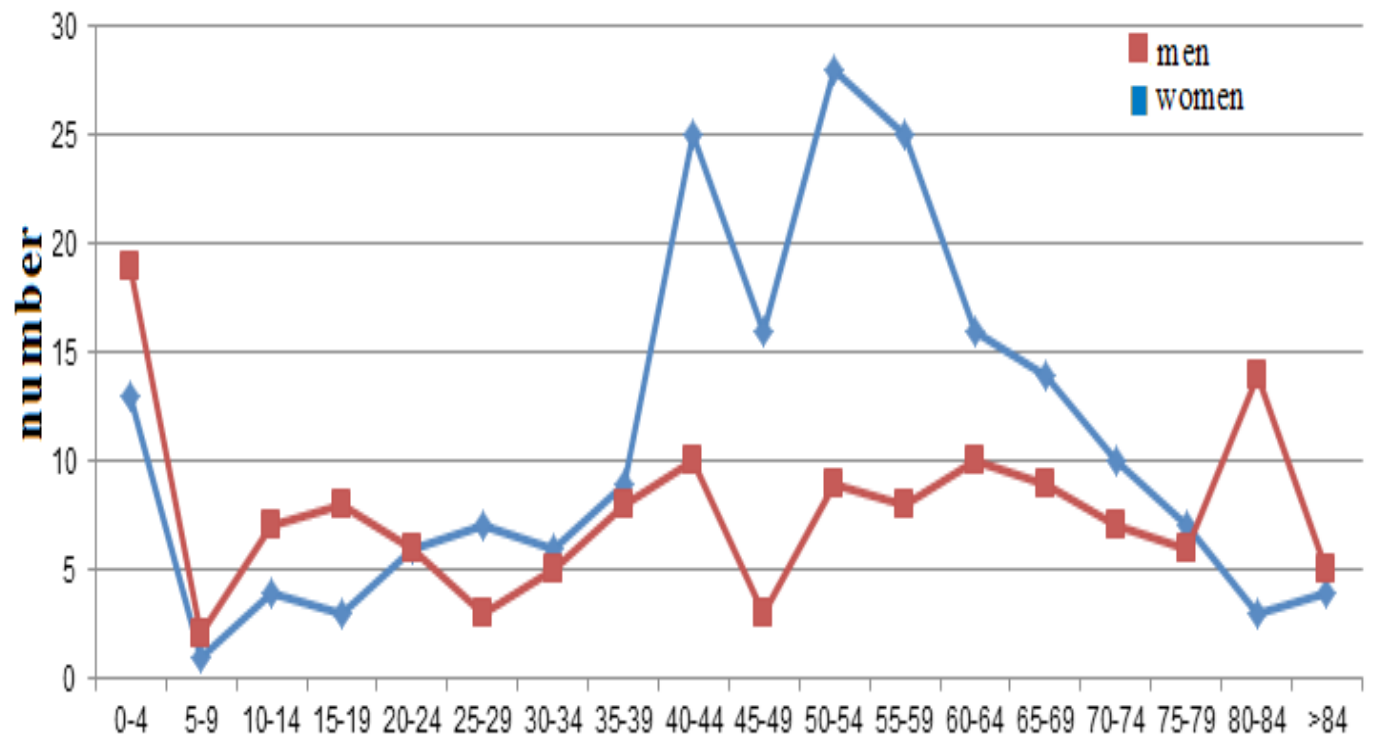

The most common methods of TB detection in patients included visiting out-patient departments for problems (220 cases), TB contacts examinations (50 cases), preventive medical checks (18 cases) and checking the registered TB patients (16 cases) (Fig. 4).
The highest TB prevalence was in the Presov Region (PO, 13.07/100,000 population) and in the Kosice Region (KE, 8.05/100,000 population) in Eastern Slovakia with the highest proportion of Roma population; and the lowest in the Trnava 
Fig. 4 Methods of TB patient detection, 2014 (adapted according to National TB Registry, 2014)

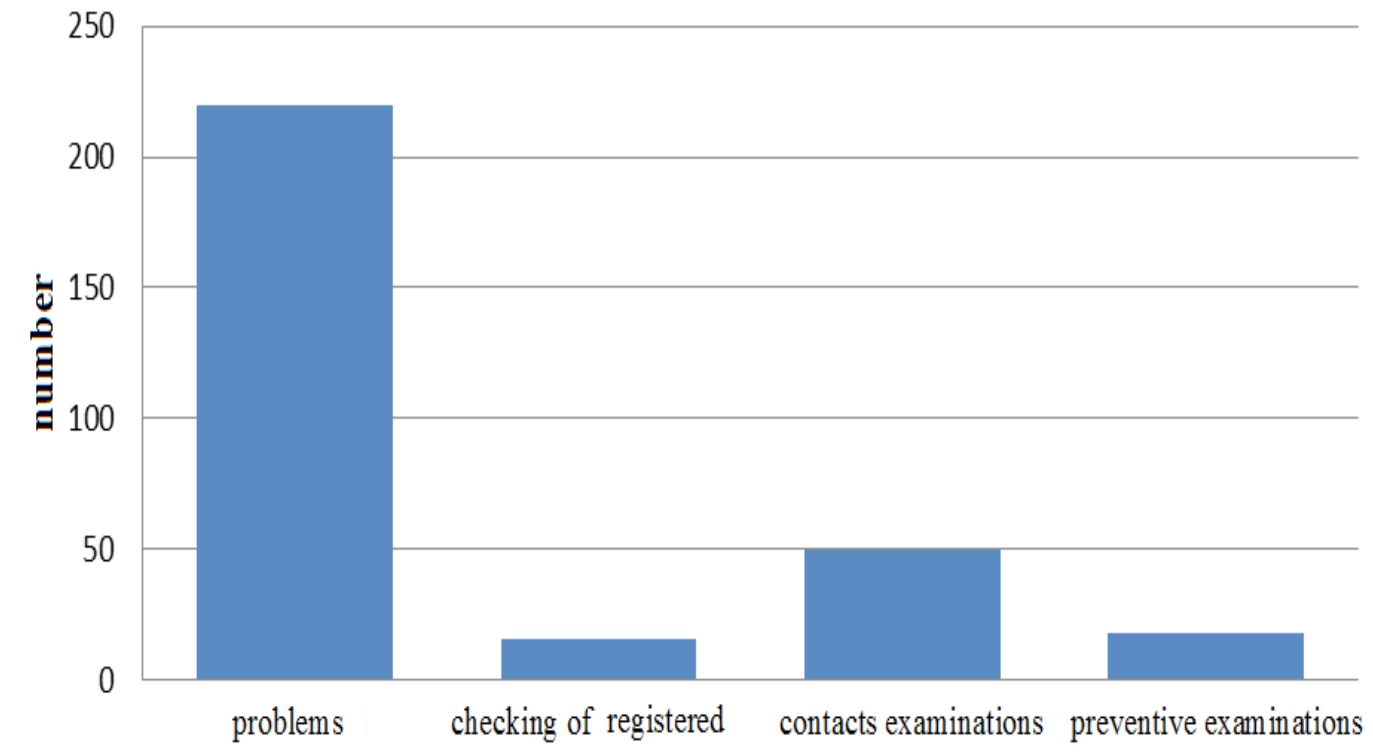

Region (TT, 3.23/100,000 population) (Fig. 5).

Over the years 2004 - 2014, the highest TB prevalence in the Presov Region was in 2007 (25.76/100,000 population) and the lowest in 2010 (12.64/100,000 population). In 2014, the TB prevalence in the Presov Region was 13.07/100,000 population (Fig. 6).

The highest TB prevalence in the Presov Region was in the Kezmarok District (24/100,000 population) and the lowest in the Levoca District (1/100,000 population). Over the years 2005 - 2014, the highest TB prevalence in the Presov Region was in the Presov District in the year 2006 (37/100,000 population) (Fig. 7).

The highest proportion of TB cases in the Roma population was in the Presov (51.4\%); Banska Bystrica (36.4\%); Kosice Regions (29.7\%) (Fig. 8).

The Roma population had $100 \%$ rate on the TB prevalence in the 5 - 9 years age group; followed by the 10 - 14 years age group (90\% rate); by the 15 - 19 years age group (81\% rate) (Fig. 9).
The TB prevalence in childhood has been increasing since 2010. In 2014, TB was diagnosed in 45 children, of which 39 cases were Roma children (Fig. 10).

The highest TB prevalence in childhood was in the Presov (PO, 22.24/100,000 population) and Banska Bystrica Regions (BB, 4.35/100,000 population). No childhood TB cases were recorded in the Trnava (TN), Zilina (ZA) and Bratislava (BA) Regions (Fig. 11).

Over the years 2003 - 2014 the highest TB prevalence in Slovak prisons was in the year 2007 (34 cases) (Fig. 12).

In 2014, the Slovak Republic achieved the highest rate of successful treatment $(85 \%)$ of newly diagnosed and microscopically confirmed TB cases in European countries. The lowest success in the TB treatment was in Croatia (only 12\%) (Fig. 13).

The most deaths in TB patients (with no TB cause of death) in Slovakia was in 2007 (47 cases) and the less in 2014 (13 cases). The most deaths caused by TB was in 2008 (10 cases) and the least in the years 2010 2012 (5 cases per year) (Fig. 14). 
Fig. 5 The TB prevalence by Regions in Slovakia and in neighboring countries (the number of cases per 100,000 population), 2014 (adapted according to National TB Registry, 2014)

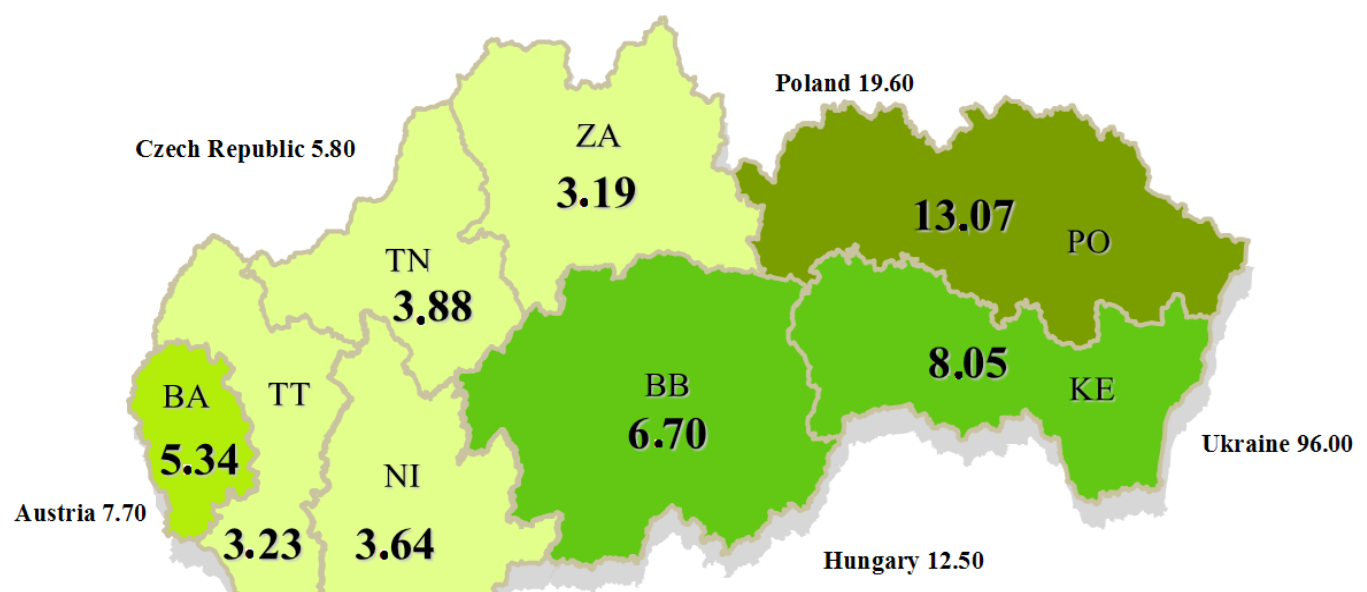

Fig. 6 The TB prevalence in the Presov Region, 2004 - 2014 (the number of cases per 100,000 population) (adapted according to National TB Registry, 2014)

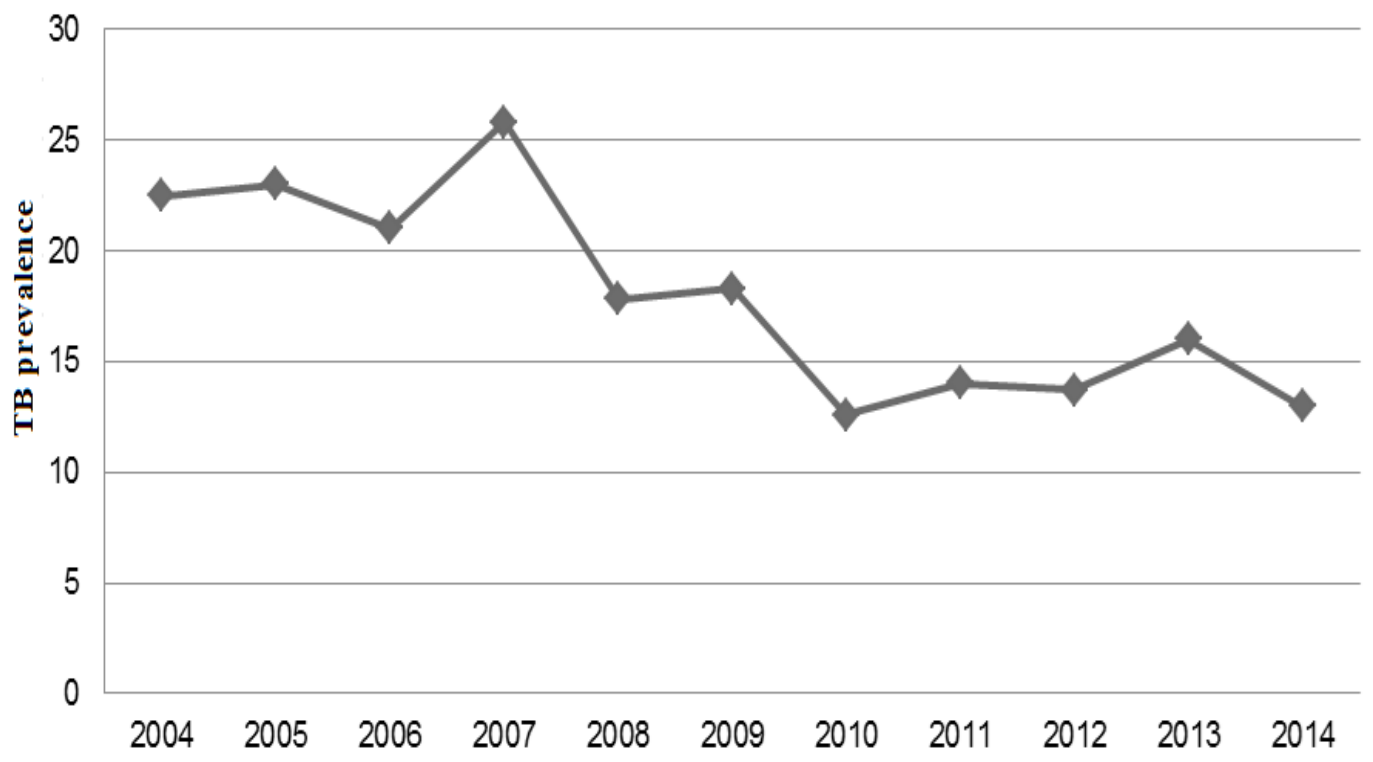


Fig. 7 The TB prevalence in the Presov Region, 2005 - 2014 (the number of cases per 100,000 population), (adapted according to National TB Registry, 2014)

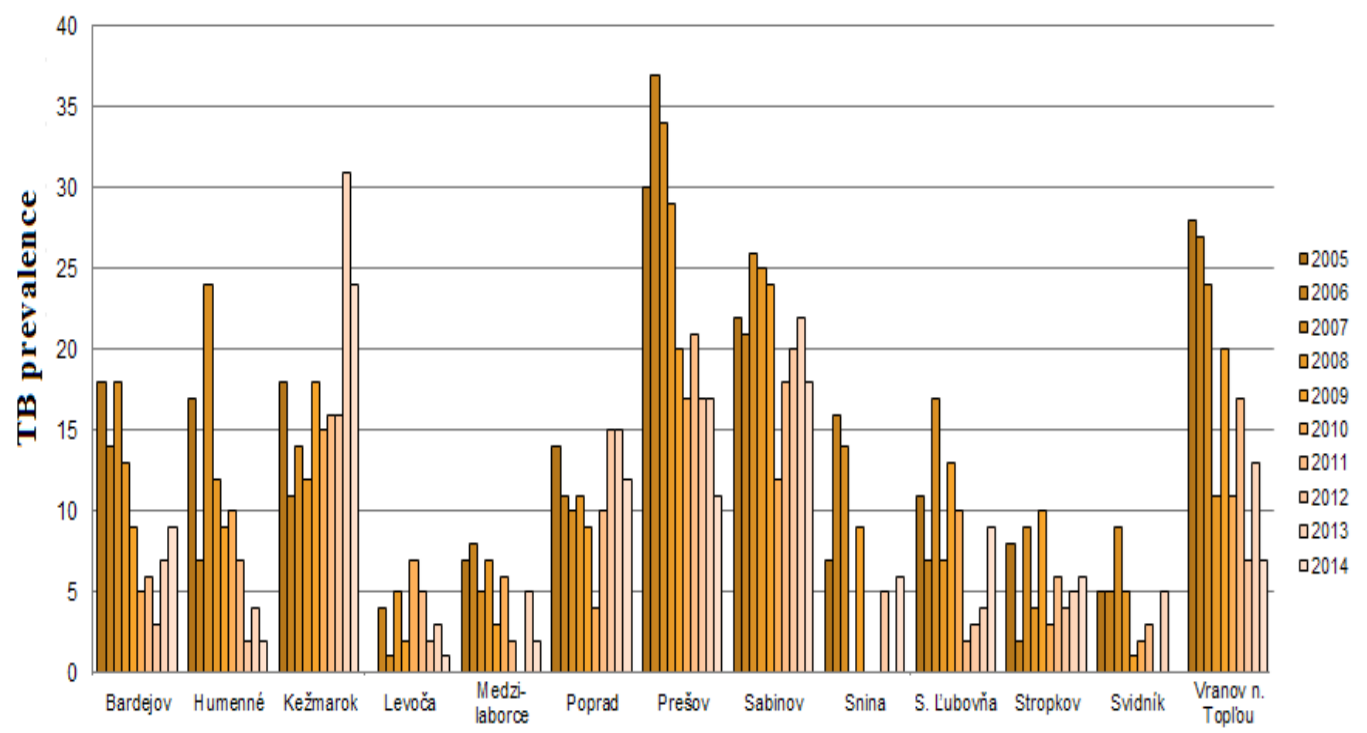

Fig. 8 The TB cases in the Roma population in Slovakia, 2014 (adapted according to National TB Registry, 2014)

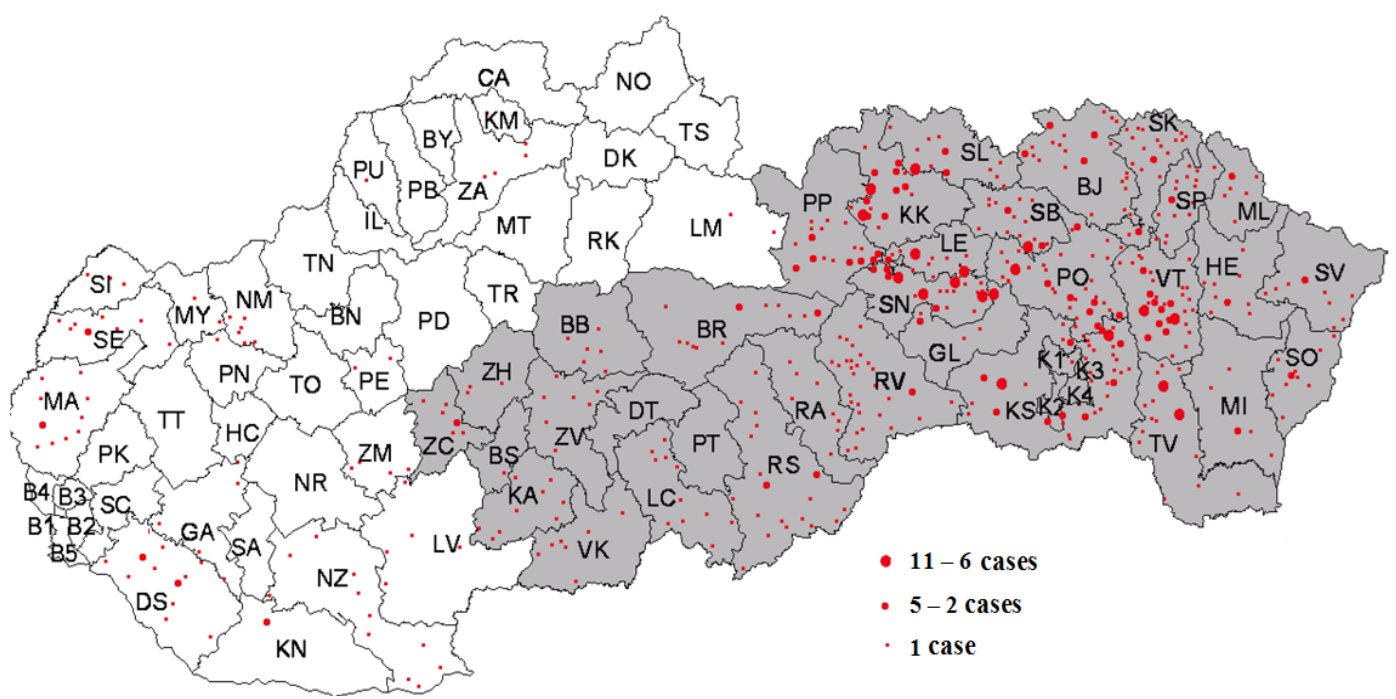


Fig. 9 The Roma ethnic group percentage in the TB prevalence, 2014 (adapted according to National TB Registry, 2014)

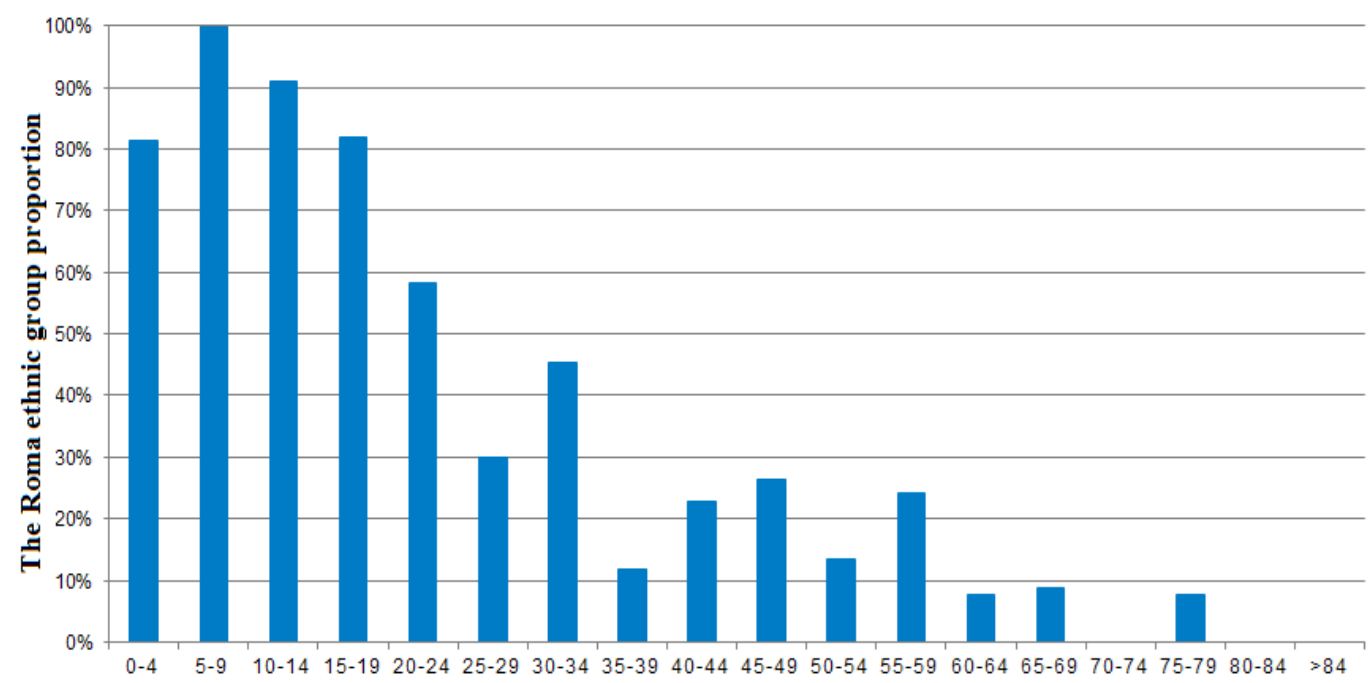

Fig. 10 The TB cases in childhood, 2014 (adapted according to National TB Registry, 2014)

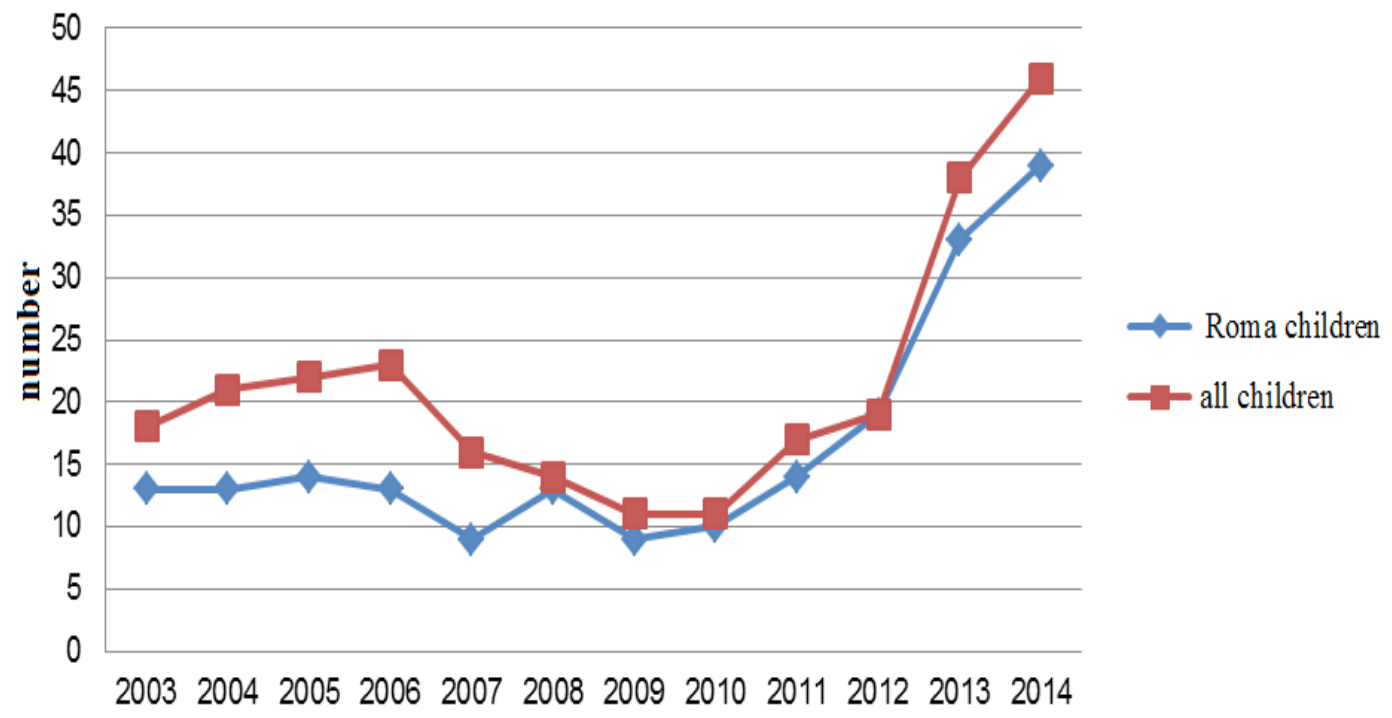


Fig. 11 The TB prevalence in childhood in Slovakia Regions, 2014 (adapted according to National TB Registry, 2014)

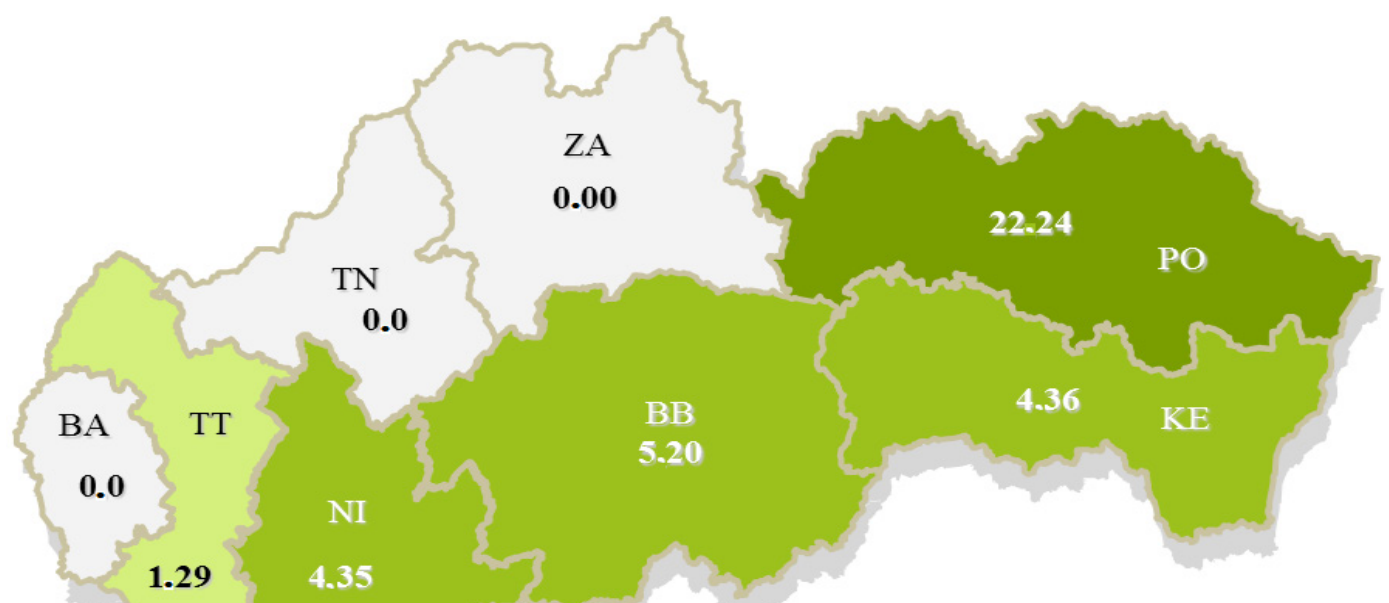

Fig. 12 The TB cases in Slovak prisons, 2003 - 2014 (adapted according to National TB Registry, 2014)

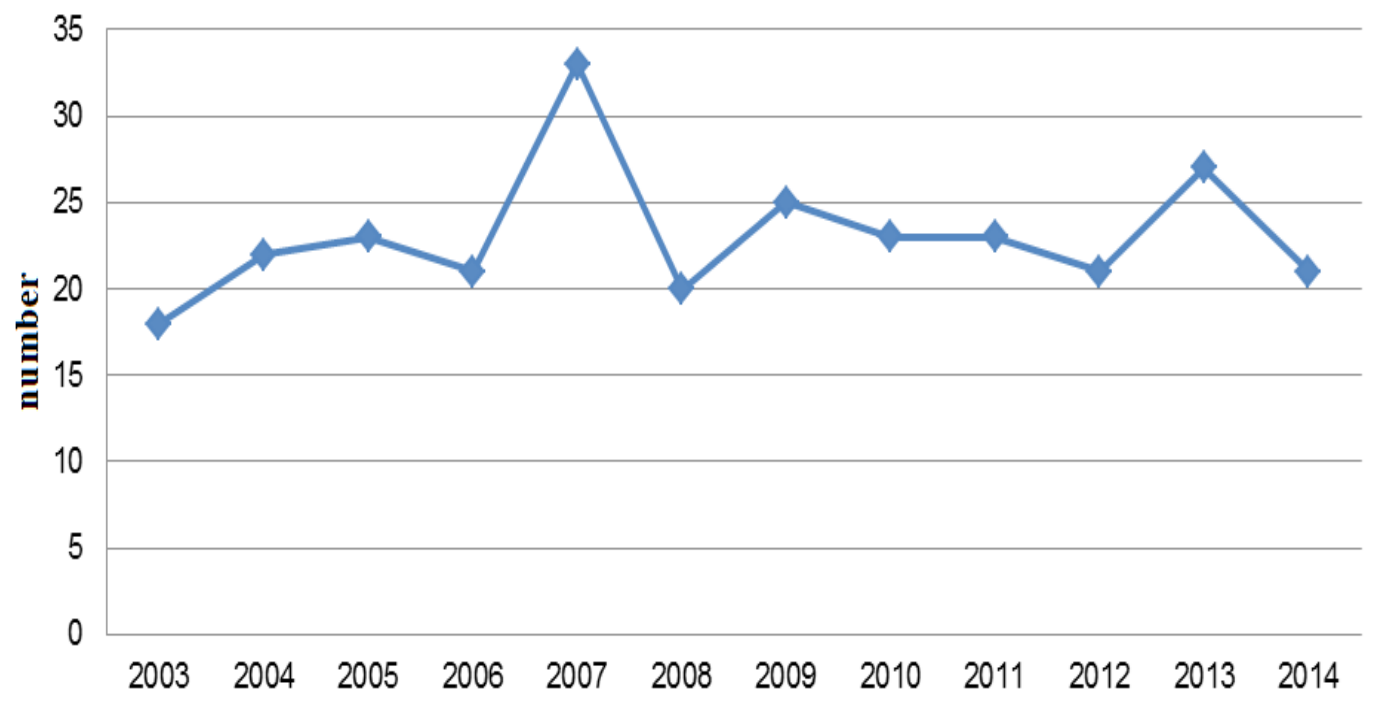


Fig. 13 The successful TB treatment rate (\%) in selected European countries, 2014 (adapted according to National TB Registry, 2014)

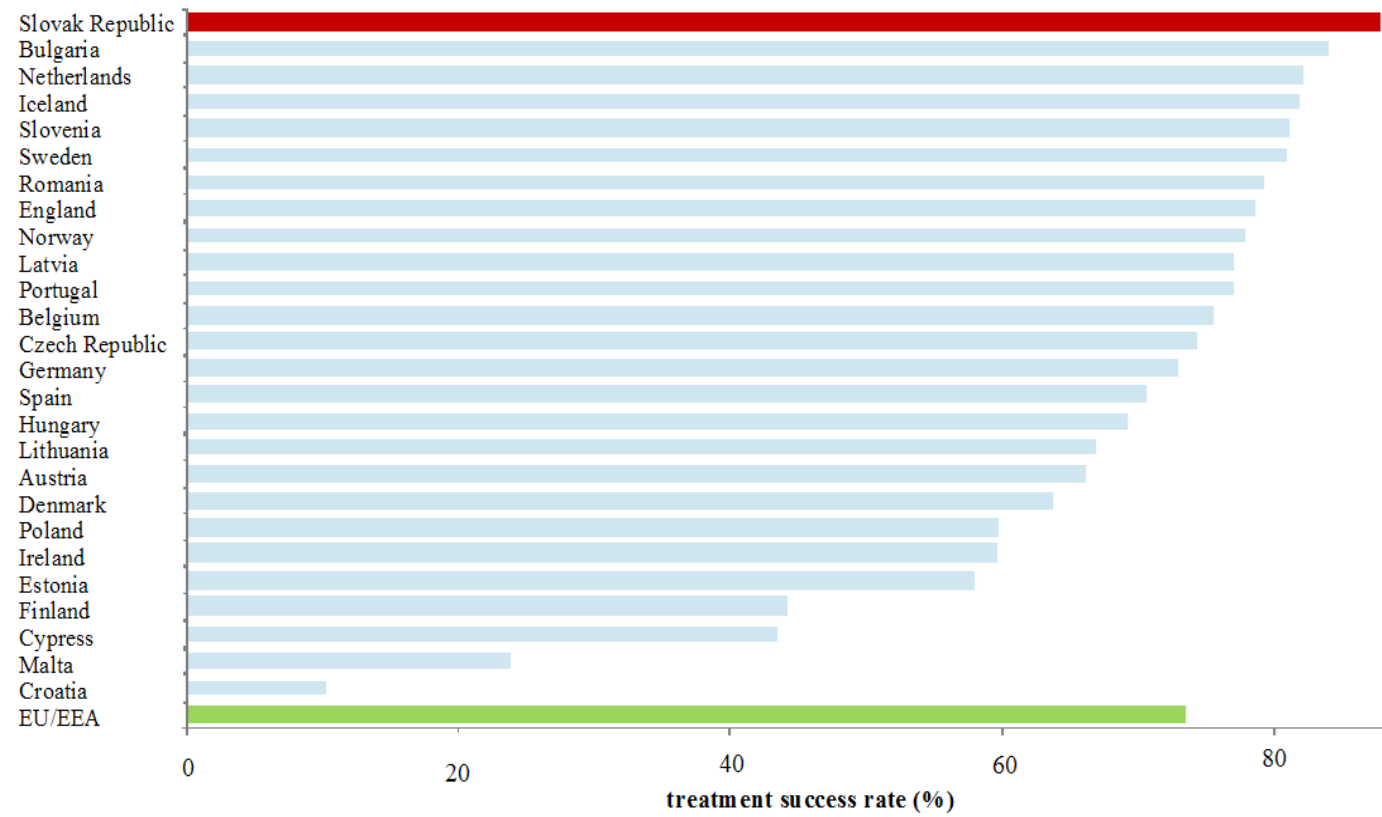

Fig. 14 The number of deaths in TB patients in Slovakia, 2007 - 2014 (adapted according to National TB Registry, 2014)

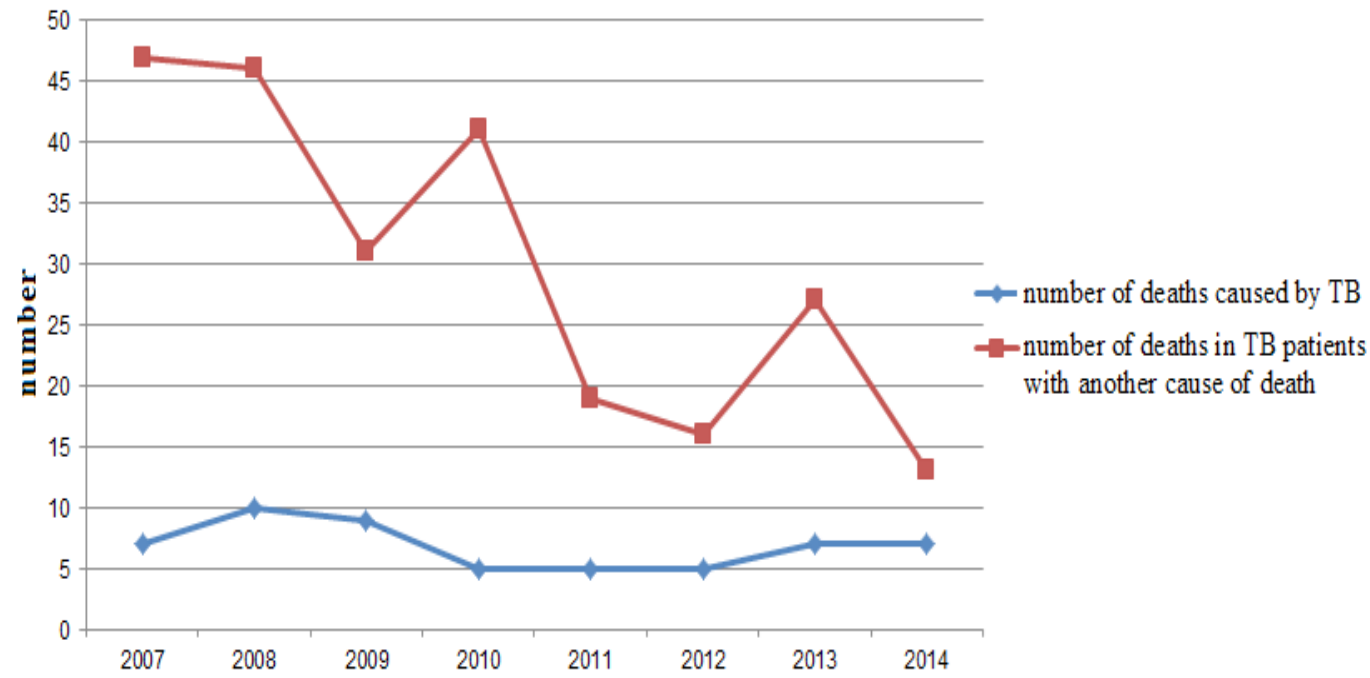


The highest TB prevalence in the elderly $(65+)$ was in the Presov Region (PO, 21.21/100,000 population) and in the Bratislava Region (BA, 16.54/100,000 population), the lowest in the Zilina Region (ZA, 4.53/100,000 population) (Fig. 15). in the Presov and Kosice Regions (in the eastern part of Slovakia with the highest proportion of Roma people) and the lowest in the Trnava Region. The highest TB prevalence in the Presov Region was in the Kezmarok District and the lowest in the Levoca

Fig. 15 The TB prevalence in the elderly (65+) in Slovakia, 2014 (adapted according to National TB Registry, 2014)

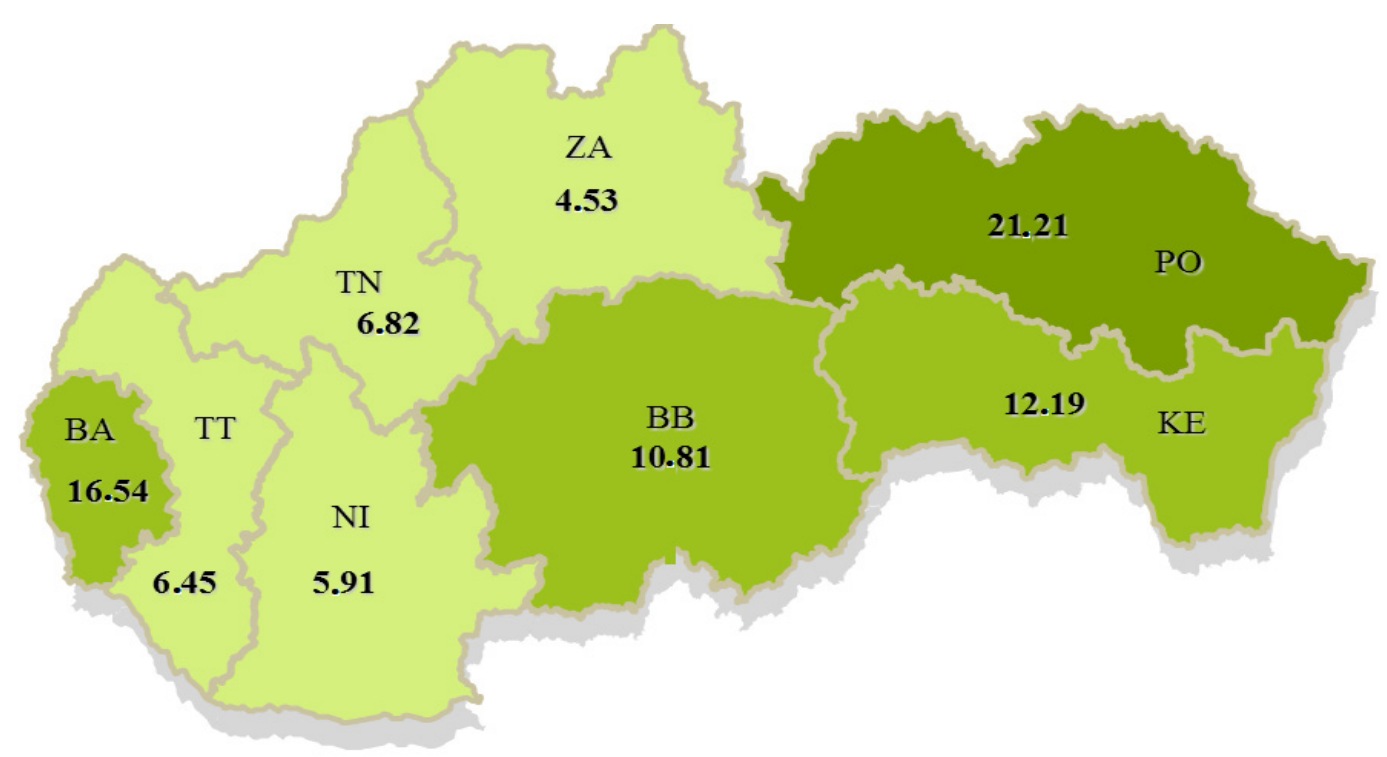

\section{Conclusion}

The epidemiology of TB in the Slovak Republic in the year 2014 was analyzed. Since 1960, TB prevalence has been reduced. The percentage of pulmonary TB occurrence was $95 \%$, with the highest prevalence in 1993. The TB prevalence decreased by $1.21 / 100,000$ compared to the year 2013.

The most common methods of TB detection in patients included visiting out-patient departments for health problems; TB contacts examinations; preventive medical checks; and checking the registered TB patients.

In 2014, the highest TB prevalence was
District. The highest TB prevalence in children was in the Presov and Banska Bystrica Regions. The Trnava, Zilina and Bratislava Regions have not reported any TB cases in children.

The Slovak Republic achieved the highest rate of successful TB treatment (85\%) in Europe. Tuberculosis is an airborne disseminated illness. It is a curable disease, however, in neglected cases and/or cases treated too late with severely attacked lung or other organs, TB can be fatal. Multi-resistant forms with their increasing incidence are problematic.

In the Slovak Republic, the TB incidence has a decreasing tendency in recent years, but nevertheless, more attention 
should be paid to finding and treating the patients, particularly in high-risk population groups.

\section{References}

1. AHLBURG D (2000) The economic impact of tuberculosis. Geneva: World Health Organization.

2. DYE C, SCHEELE S, DOLIN $\mathrm{P}$ et al (1999) Consensus statement. Global burden of tuberculosis: Estimated incidence, prevalence, and mortality by country. WHO Global Surveillance and Monitoring Project. JAMA 282: 677-686.

3. DYE C (2006) Global epidemiology of tuberculosis. Lancet 367(9514): 938-940.

4. European Center for Disease Prevention and Control (2010) World Health Organization.

5. Tuberculosis surveillance and monitoring in Europe (2012) Stockholm: European Center for Disease Prevention and Control.

6. FRIEDEN TR, STERLING TR, Munsiff SS et al (2013) Tuberculosis. Lancet 362: 887899.

7. GLAZIOU P, FALZON D, FLOYD K et al (2013)Global epidemiology of tuberculosis. Semin' Respir Crit Care Med. 34(1): 3-16.

8. GUPTA R, ESPINAL MA, RAVIGILONE MC (2004) Tuberculosis as a major global health problem in the 21 st century: A WHO perspective. Semin Respir Crit Care Med. 25:245-253.
9. MAHER D, RAVIGLIONE M (2005) Global epidemiology of tuberculosis. Clin Chest Med 26: 67-182.

10. MATHEMA B, KUREPINA NE, Bifani PJ et al (2006) Molecular Epidemiology of Tuberculosis: Current Insights. Clin Microbiol Rev.19(4): 658-685.

11. Regional Public Health Administration (2014) March 24th - World Tuberculosis Day. [online] RPHA: Trencin. [updated 2014 November; cited April 9, 2015]. Available at: http://www.ruvztn.sk/SDT_2014. pdf.

12. SOLOVIC I (2014) Tuberculosis at the beginning of the 21 st century - a practical view. Via Practica 4: 215-219.

13. SOLOVIC I, BANSKA K, BARBORICOVA Z et al (2008) Tuberculosis - selected Chapters. Vysne Hagy: ITLD\&TS 198 p. ISBN 978-80-970024-4-2.

14. ZANOVA E, KOZAKOVA D, RYBAR I et al (2012) The conversion of quantiferon TB gold test during biological treatment by anti-TNF preparations. In Annual European Congress of Rheumatology. Berlin: Rheumatology European Congress p. 1.

15. ZANOVA E, KOZAKOVA D, POLANOVA $M$ et al (2012) Diagnosis of latent tuberculosis before starting biologic treatment. Annual Meeting Proceedings 56th congress of Czech-Slovak Rheumatologists. Prague: Czech Rheumatological Society ISBN 97880-260-2901-1 p 1. 